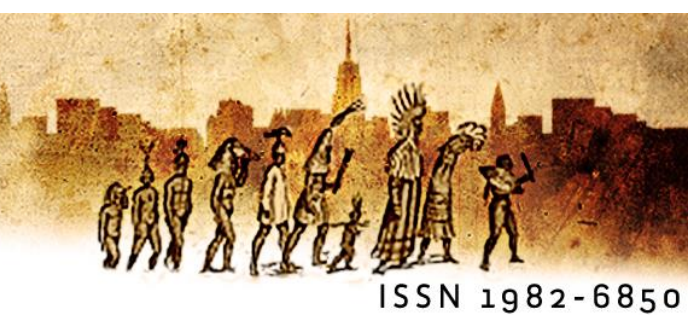

\title{
Desenvolvimento profissional: um olhar sobre as práticas de formação docente realizadas por coordenadores em escolas públicas de São Paulo
}

\section{Desarrollo profesional: una mirada en las prácticas de formación docente realizadas por coordinadores en escuelas públicas de São Paulo}

Jeanny Meiry Sombra Silvai (PUC-SP)

Resumo: Este artigo traz recortes de uma pesquisa de doutorado cujo objetivo foi conhecer e analisar práticas formativas empregadas por coordenadores pedagógicos das escolas públicas da rede estadual de ensino, na cidade de São Paulo. Os sujeitos participantes foram 402 coordenadores do Ensino Fundamental e Médio. Os métodos mistos foram utilizados como procedimentos metodológicos e permitiram combinar olhares quantitativos e qualitativos à pesquisa, quais foram: Survey, observação e entrevista narrativa. Os dados foram fundamentados em García (1999), Marcelo (2009), Imbernón (2011), André (2016), dentre outros autores do campo da formação docente que discutem o tema do desenvolvimento profissional. $O$ estudo apontou que os coordenadores têm diferentes entendimentos do que são estratégias de formação e revelou que a seleção e/ou elaboração de estratégias de formação está fundada, em grande medida, em teorias implícitas e idiossincrasias, assim como em familiaridades presumidas com o ofício e formações advindas de órgãos centrais da SEE-SP. O estudo evidenciou, ainda, que em muitas das estratégias empregadas pelos coordenadores estão presentes princípios de formação voltados para o desenvolvimento profissional dos professores, ainda que o conceito de desenvolvimento profissional não seja claro para muitos coordenadores.

Palavras-chave: Desenvolvimento Profissional; Coordenador pedagógico; Formação docente; estratégias de formação.

Resumen: Este capítulo presenta extractos de una investigación doctoral cuyo objetivo era conocer y analizar las prácticas de capacitación empleadas por los coordinadores pedagógicos de las escuelas públicas en el sistema escolar estatal, en la ciudad de São Paulo. Los sujetos 
participantes fueron 402 coordinadores de primaria y secundaria. Los métodos mixtos se utilizaron como procedimientos metodológicos y permitieron combinar puntos de vista cuantitativos y cualitativos para la investigación, que fueron: Survey, observación y entrevista narrativa. Los datos se basaron en autores del campo de la formación docente que discuten el tema del desarrollo profesional. El estudio señaló que los coordinadores tienen una comprensión diferente de qué son las estrategias de capacitación y reveló que la selección y / o elaboración de estrategias de capacitación se basa, en gran medida, en teorías e idiosincrasias implícitas, así como en familiaridades asumidas con la profesión y formaciones de órganos centrales de SEE-SP. El estudio también mostró que en muchas de las estrategias utilizadas por los coordinadores existen principios de capacitación dirigidos al desarrollo profesional de los docentes, aunque el concepto de desarrollo profesional no está claro para muchos coordinadores.

Palabras clave: Desarrollo profesional; Coordinadora pedagógica; Formación de profesores; estrategias de formación.

\section{Introdução}

As exigências decorrentes das rápidas mudanças em nossa sociedade, seja pelo progresso científico ou tecnológico, seja pelo ensino hibrido ou tradicional, dentre outros, impossibilita a concepção da formação de professores como um processo estanque, estático e esgotável. A formação continuada de professores é um processo contínuo, sistemático que abarca toda a carreira docente. Tal formação é parte integrante do desenvolvimento profissional (GARCIA,1999). A escola é um local privilegiado para formação continuada; é no espaço de trabalho que os profissionais mais aprendem sobre a própria profissão (CANÁRIO, 2010).

Os procedimentos formativos adotados pelo coordenador pedagógico (CP) em reuniões de formação continuada com os professores podem favorecer a aprendizagem docente e contribuir para o desenvolvimento profissional do professor, por isso é importante que o CP conheça e faça uso de diferentes estratégias formativas (SILVA, 2019). O que orienta a ação do CP é a concepção de formação, dessa forma é importante compreender as teorias implícitas em sua ação, fundamentá-las, revisá-las e reconstruí-las.

Para que a formação que ocorre na escola contribua para o desenvolvimento profissional do professor é importante que os encontros possibilitem a reflexão sobre a prática de sala de aula. Mas será que isso de fato tem ocorrido nas escolas? Se o que 
queremos é a ressignificação da prática do professor para ajudá-lo em seu desenvolvimento profissional,

Três condições são necessárias para conduzir mudanças conceituais, nas teorias pessoais ou, ainda, em crenças. A primeira delas refere-se à possibilidade de os professores terem oportunidade de considerar o porquê de novas práticas e refletir sobre os valores e crenças a elas associadas são melhores do que seus enfoques anteriores. A segunda diz respeito a observar exemplos destas novas práticas e, preferencialmente, vivenciálas. A terceira condição está relacionada a ideia de que os professores necessitam de apoio e orientação para empreenderem mudanças, sobretudo aqueles que estão em início de carreira (MIZUKAMl; REALI, 2002, p. 77).

Com o interesse de conhecer como de fato estão sendo realizados os encontros formativos nas escolas, este estudo buscou ouvir 402 coordenadores da rede pública estadual de ensino da capital paulista, bem como observar as reuniões de formação de quatro coordenadores em quatro escolas. Para este artigo, será feito um recorte da pesquisa original com objetivo de responder as seguintes questões: Quais estratégias formativas estão sendo utilizadas pelos coordenadores pedagógicos? Será que tais estratégias criam condições para promoção do desenvolvimento profissional dos professores? O texto está dividido em três partes. Na primeira discorreremos sobre o conceito de desenvolvimento profissional; na segunda, aspectos metodológicos da pesquisa. Na sequência, apresentaremos a discussão de parte dos dados seguidos das considerações finais.

\section{A formação docente com foco no desenvolvimento profissional}

As investigações recentes que estão conquistando consenso entre profissionais da educação, vêm centrando suas discussões no conceito de desenvolvimento profissional docente. Por exemplo, Huberman (1995) em seus estudos sobre o ciclo de vida profissional dos professores, descreve fases que caracterizam o percurso formativo. Considera que existem grandes diferenças de anseios e necessidades entre o docente em fase inicial, entre o que adquiriu uma considerável experiência pedagógica e o que já se encaminha para a aposentadoria. O autor chama a atenção para o fato de que as sequências estabelecidas na descrição da carreira docente ocorrem de maneira continua, ou seja, pressupõe uma 
aprendizagem ao longo de toda a vida, em contextos diversificados, em que o professor assume o papel de protagonista dos conhecimentos adquiridos em cada uma das fases. Assim, o desenvolvimento de uma carreira é um processo e não uma série de acontecimentos.

Na mesma direção, Carlos Marcelo (2009) considera que o conceito de desenvolvimento tem uma conotação de evolução e continuidade e define o termo desenvolvimento profissional como um percurso evolutivo de aperfeiçoamento da prática docente que engloba não apenas o professor, mas também toda a comunidade escolar.

Nessa perspectiva, não é mais possível entender a formação docente como dois momentos separados: a formação inicial que ocorre no contexto acadêmico e é responsável pelos conhecimentos básicos e elementares do professor e a continuada, vista como uma etapa que ocorre após o ingresso na docência, como uma forma de ascender na carreira, e que muitas vezes é concebida como um meio de acumulação de cursos, conhecimentos ou técnicas.

Essa separação historicamente marcou a concepção tradicional da formação docente trazendo consequências negativas para a carreira do magistério. "Essa separação cristalizou a ideia de que ao terminar a formação inicial a pessoa estaria formada, o que resultou em muitas críticas à formação inicial e até em abandono da profissão" (ANDRÉ, 2016, p. 30).

Justamente rompendo com a tradicional justaposição entre formação inicial e continuada, os autores vêm centrando suas discussões no conceito de desenvolvimento profissional docente. Essa preferência é justificada por Carlos Marcelo (2009), pois marca mais claramente a concepção de profissional do ensino que se forma ao longo da carreira e que integra diferentes tipos de oportunidades e experiências. O autor afirma "O conceito de desenvolvimento profissional tem vindo a modificar-se durante a última década, sendo essa mudança motivada pela evolução da compreensão de como se produzem os processos de aprender e ensinar". (Idem, p. 10). A esse respeito, André (2016, p. 30) explica que

A concepção que temos hoje é a de que a formação inicial é apenas uma fase de um processo de desenvolvimento profissional, que se prolonga ao longo de toda a vida profissional. Quem se dispõe a trabalhar como docente deve entender que continuará seu processo de aprendizagem ao longo da vida, pois a docência exige estudo e aperfeiçoamento profissional para que possa responder às demandas da educação escolar inserida em uma realidade em constante mudança. 
Assim, a ideia é superar a retórica do inacabamento presente no termo formação continuada para assumir uma perspectiva mais emancipatória. Dessa forma, os termos formação inicial e formação continuada estão sendo substituídos gradativamente na literatura do campo da formação de professores por desenvolvimento profissional docente.

Contudo, mais importante do que a alteração dos termos é entender de que forma o conceito de desenvolvimento profissional afeta a concepção de formação docente. García (1999) explica que o conceito de desenvolvimento profissional docente pressupõe uma abordagem na formação de professores que valorize o seu caráter contextual, organizacional e orientado para a mudança. "Esta abordagem apresenta uma forma de implicação e de resolução de problemas escolares a partir de uma perspectiva que supera a característica tradicionalmente individualista das atividades de aperfeiçoamento dos professores" (Id., p. 137).

Dessa forma, o contexto de trabalho docente passa a ser o lócus privilegiado para as ações de formação. Pensando no potencial formativo do contexto de trabalho para o desenvolvimento profissional de professores, Canário (1998) destaca a importância de se conceber a formação como um processo de aprendizagem coletiva do qual emergem novas competências. O autor considera que a formação centrada na escola atribui grande valor aos saberes adquiridos por via experiencial, que desempenham um papel de âncora na realização de novas aprendizagens. Nesse sentido, valorizar a experiência significa aprender a aprender com a experiência. A pertinência da formação centrada na escola tem como base o pressuposto de que os professores aprendem a sua profissão nas escolas e que essa aprendizagem coincide com um processo largo, contínuo e multiforme, de socialização profissional. Afirma ainda que a formação centrada na escola promove a ideia de formação da equipe "no sentido de se transformarem em comunidades profissionais de aprendizagem, marcadas por uma cultura colaborativa" (Idem, p. 17), superando os modelos que centravam a atenção apenas no professor como indivíduo, deslocado de seu contexto de ação.

Nóvoa (1995), ao afirmar, de um modo geral, que os programas de formação têm ignorado tanto o desenvolvimento pessoal do professor, quanto a articulação entre a formação e os projetos das escolas, para adquirir como eixo de referência o desenvolvimento profissional, constata que, tanto numa perspectiva individual como 
coletiva, é necessário considerar três dimensões: produzir a vida do professor (desenvolvimento pessoal), produzir a profissão docente (desenvolvimento profissional) e produzir a escola (desenvolvimento organizacional). Essas dimensões são importantes para adquirir como eixo de referência o desenvolvimento dos professores na dupla perspectiva: do professor individual e do coletivo docente.

Para produzir a vida do professor, o autor propõe a formação na perspectiva críticoreflexiva que fornece aos professores os meios de um pensamento autônomo e conduz à dinâmica de autoformação participada, possibilitando a troca de experiências, a partilha e a produção desses saberes, transformando o professor no construtor de sua formação. Produzir a profissão docente envolve "[...] valorizar paradigmas de formação que promovam a preparação de professores reflexivos, que assumam a responsabilidade do seu próprio desenvolvimento profissional e que participem como protagonistas na implementação das políticas educativas." (Id., p. 27). Para isso é necessário produzir a escola como espaço de trabalho e formação, o que implica gestão democrática e práticas curriculares participativas, possibilitando a constituição de redes de formação contínua.

Assim, o item reflexão, ou o conceito de professor reflexivo, presentes nos modelos da racionalidade prática e crítica ainda é frequente na abordagem de formação para o desenvolvimento profissional. Contudo, também há uma evolução na compreensão desse termo. Como afirma André (2016, p. 20), "a ideia do professor reflexivo evoluiu ao longo do tempo para reforçar a ideia de uma escola reflexiva", cujos integrantes - alunos, professores, gestores e demais profissionais - estejam envolvidos em ações de leitura crítica da prática, não somente da sua prática individual, mas da prática social que perpassa toda a realidade do contexto em que estão inseridos.

Um dos princípios que subjazem a essa ideia-chave é o de autonomia. Pretende-se formar sujeitos autônomos, ou seja, pessoas que tenham ideias próprias, pensem por si mesmas, sejam capazes de escolher entre alternativas, decidam o caminho a ser seguido, implementem ações e tenham argumentos para defender suas escolhas e suas ações. Ao exercer sua autonomia, essas pessoas vão se sentir cada vez mais livres das amarras do poder político e econômico (ANDRÉ, 2016, p. 20).

O trabalho reflexivo sobre a prática docente é entendido como uma forma de reconstrução permanente de uma identidade pessoal e profissional em interação direta com a cultura escolar, com sujeitos do processo e com os conhecimentos acumulados sobre a área da educação. 
Na formação docente, em uma perspectiva do desenvolvimento profissional, os processos formativos são orientados para a descoberta e produção do conhecimento próprio, por meio da investigação e análise da prática educativa. Nessa abordagem, a prática educativa escolar é um marco importante para discutir teorias, além disso, são consideradas como parte do processo formativo as diferentes experiências individuais e coletivas vivenciadas pelos professores, como pessoas e profissionais.

Para Nóvoa (1995), todo processo de formação deve ter como referencial o saber docente, o reconhecimento e valorização desse saber. A esse respeito, Placco e Souza (et al, 2006, p. 86) discutem como o saber e o aprender estão mutuamente imbricados no processo reflexivo da prática cujo "aprender envolve atribuir significações e engendra relações únicas com o saber. [...] as experiências, podem constituir-se em saberes e, a um só tempo, ser significadas por esses saberes e gerar novos saberes, em um movimento constante e contínuo". Em vista disso, ressaltam que o formador de professores, no caso o coordenador pedagógico, deve levar em consideração os saberes do grupo de professores da escola e "oferecer pistas para que novas atribuições de significado possam ser realizadas pelos sujeitos" (Id., p. 86).

O aprendizado profissional configura-se, portanto, como um processo permanente de construção de saberes e competências para a realização do trabalho docente que não se encerra na formação inicial, mas se faz presente ao longo de sua trajetória pessoal e profissional.

Essa compreensão implica a necessidade das instituições escolares criarem espaços e tempos institucionalizados que favoreçam processos coletivos de reflexão e intervenção na prática pedagógica, através de reuniões pedagógicas, dentro da carga horária dos profissionais, construção coletiva do projeto político-pedagógico da escola e avaliação coletiva dele. Cabe, também, criar uma forma de incentivo à sistematização de práticas de formação cuja proposta esteja centrada no papel do professor como pesquisador.

Nesse aspecto, André (2016, p. 28) faz uma ressalva,

[...] a pesquisa que se faz no trabalho, voltada mais para a prática da sala de aula, para melhorar o próprio trabalho, é diferente da pesquisa que se faz como exigência de um mestrado, um doutorado, uma pesquisa acadêmica com outra finalidade. O objeto é diferente, a academia tem um compromisso com o avanço da teoria, a pesquisa da prática volta-se para a realidade para conhecê-la melhor e modificá-la. Ambas, porém, exigem rigor na concepção, no desenvolvimento e na comunicação. 
Dominando os instrumentos e processos da pesquisa, os professores poderão, por exemplo, sistematizar melhor suas experiências educativas exitosas e socializá-las tanto entre seus pares na escola, como nos veículos próprios das comunidades acadêmicocientíficas da área da educação. Quando a escola abre espaço para ações desse tipo, o processo formativo pode-se constituir num instrumento poderoso de fortalecimento da profissão docente. Conforme Zeichner (1998) é necessário eliminar a linha divisória entre pesquisadores acadêmicos e professores. O autor considera que a academia pode ser um espaço onde professores e pesquisadores tenham oportunidades de interlocução, gerando, compartilhando conhecimentos, no contato com realidades diferentes e ampliando a compreensão do processo educativo e formativo.

A ideia de professor pesquisador também sofreu ajustes à medida que estudos foram contribuindo para delinear o papel da investigação feita pelo professor. Conforme André (2016, p. 28), a visão atual desse conceito é de que a pesquisa seja realizada em colaboração, "para a constituição de comunidades investigativas". A autora conclui ainda que "esses conceitos de professor e escola reflexiva, de pesquisar a prática em colaboração, precisam ser discutidos em um quadro dinâmico de crescimento contínuo, de aprendizado ao longo da vida. Aí surge o conceito de desenvolvimento profissional." (idem, p. 30)

Implementar na escola ações de formação voltadas para o desenvolvimento profissional docente exigirá, portanto, que o coordenador pedagógico desenvolva "um plano sistemático para melhorar a prática de trabalho, as crenças e conhecimentos profissionais com o propósito de aumentar a qualidade docente, investigativa e de gestão" (IMBERNÓN, 2010, p. 47). Tal plano sofrerá entraves ou correrá o risco de esavaziar seu sentido se não houver parceria da gestão na formação.

Conforme problematiza Oliveira-Formosinho (2009, p. 228): "Que o bom ensino produz melhor aprendizagem, ninguém provavelmente discordará. A discordância surge quando quiser se chegar ao acordo sobre o que é bom ensino.". Neste estudo, não há discordância, defendemos como boa: a formação para o desenvolvimento profissional que se baseia

na concepção de um professor pesquisador, que vai se orientar para compreender as teorias implícitas na ação, fundamentá-las, revisá-las e reconstruí-las. Isso exige um aprendizado de leitura crítica da prática, de 
análise fundamentada da situação para entendê-la e encontrar caminhos para reestruturá-la, tornando-a melhor (ANDRÉ, 2016, p. 32).

Resta saber se a formação docente, realizada na escola, tem contemplado os conceitos discutidos até o momento.

\section{A pesquisa: aspectos metodológicos}

O estudo utilizou o que Moscoso (2017, p. 633) caracteriza como "pesquisa com métodos mistos", na qual dados quantitativos e qualitativos são usados de forma complementar visando atribuir sentidos e responder às questões da pesquisa de forma consistente e confiável. Assim, a pesquisa associou duas dimensões: uma que cobriu um maior volume de dados por meio de survey realizada com 402 coordenadores e outra mais delimitada que permitiu um olhar aprofundado para o objeto de estudo. Esta última se consistiu na observação in loco em quatro escolas da capital paulista e entrevistas com seus coordenadores. O objetivo foi coletar informações sobre as estratégias de formação docente utilizadas por esses profissionais nas reuniões pedagógicas semanais que ocorrem nas escolas. Neste artigo nos deteremos a um recorte da Survey.

A ação formadora, ou seja, a condução da formação realizada pelo coordenador durante a reunião coletiva foi o objeto da pesquisa. Na Rede pública estadual de ensino de São Paulo, o momento de reunião coletiva ocorre por meio da chamada Aula de Trabalho Pedagógico Coletivo - ATPC ${ }^{1}$. O objetivo primordial dessas reuniões é criar um espaço de discussão e formação para fortalecer o projeto político-pedagógico da escola. Isso significa articular as disciplinas, estudar, atender a problemas enfrentados pelos docentes, trocar experiências, discutir planejamento e avaliação e estimular a reflexão sobre a prática docente. Para que isso aconteça, é importante haver uma boa estrutura para discussão coletiva, com objetivos e cronogramas.

O sujeito de nosso estudo, o coordenador pedagógico (CP), desempenha nesse contexto o papel fundamental de planejar, organizar e conduzir o encontro; possibilitando boas situações de aprendizagem entre todos. Temos clareza de que a dinâmica do encontro

\footnotetext{
${ }^{1}$ Em 2012, para adequar a carga horária dos docentes com a Lei Federal № 11.738/2008, foi publicada a Resolução SE No o8, que passa a chamar a HTPC de Aula de Trabalho Pedagógico Coletivo (ATPC). Assim, cada ATPC corresponde ao tempo de aula oferecida aos alunos: 50 minutos.
} 
não se deve unicamente a esse profissional, no entanto, cabe a ele elaborar a pauta, conduzir as discussões, selecionar as estratégias, controlar o tempo; seu modo de agir como mediador pode ditar o ritmo da reunião, favorecendo ou não a formação. De fato, espera-se que o CP assuma um papel de líder no encontro.

A transformação das reuniões que acontecem na escola em espaços de reflexão e produção de saberes sobre a docência exige uma metodologia proposta e dirigida pelo coordenador pedagógico, cuja liderança é essencial para que tais reuniões não assumam a condição de Horário de Trabalho Perdido (BRUNO; CHRISTOV, 2003, p. 61).

Assim, destacamos como foco de observação do objeto da pesquisa as ações do CP durante a reunião: ele faz formação docente? Como são suas intervenções? Utiliza estratégias formativas; se sim, quais? De que maneira esse sujeito faz as mediações entre as estratégias propostas e o grupo docente? Será que as estratégias empregadas contribuem para o desenvolvimento profissional do professor?

A Rede pública da SEE-SP conta com aproximadamente dois mil coordenadores na capital $^{2}$, nosso interesse era ouvir o maior número de profissionais, por isso optamos por elaborar uma survey e distribuir o questionário por meio das Diretorias Regionais de Ensino (DRE). Por fim, obtivemos uma participação de 402 sujeitos, desses foi necessário excluir 22 respondentes por não atenderem aos critérios deste estudo (ter no mínimo seis meses de atuação na coordenação do Ensino Fundamental e Médio); assim, considerou-se para o levantamento um total de 380 sujeitos, parcela que representa $19 \%$ da população de coordenadores da rede pública estadual, na capital paulista.

A pergunta principal do questionário foi: "Ao conduzir as reuniões de ATPC, que estratégias de formação docente você costuma utilizar? Fique à vontade para escrever o quanto desejar". Após extrair do aplicativo SurveyMonkey todas as respostas dos coordenadores para essa questão, iniciamos o processo de análise, utilizando como balizador do estudo, a técnica de Análise de Conteúdo (BARDIN, 2016). O Quadro 1 apresenta a organização das categorias ao qual chegamos.

Quadro 1 - A condução da ATPC: o que se faz, como e por quê? Um olhar para as respostas por meio da Análise de Conteúdo

\footnotetext{
${ }^{2} \mathrm{O}$ cálculo teve por base os dados fornecidos pela Escola de Formação e Aperfeiçoamento dos Professores do Estado de São Paulo (EFAP) órgão da SEE-SP que, em setembro de 2018, registrava em sua base de dados, aproximadamente, dois mil coordenadores designados na região metropolitana de São Paulo. A Resolução SE 18, de 02/5/2019 alterou o siglário da SEE-SP.
} 


\section{CATEGORIAS}

Subcategorias

\begin{tabular}{|c|c|}
\hline $\begin{array}{c}1 \\
\text { Estratégias de formação docente }\end{array}$ & $\begin{array}{l}\text { Prática docente como objeto de estudo } \\
\text { Análise de produções de alunos e propostas didáticas }\end{array}$ \\
\hline $\begin{array}{c}2 \\
\text { O que se lê e o que se vê em } \\
\text { ATPC? }\end{array}$ & $\begin{array}{l}\text { Fonte, contédo e finalidade das leituras } \\
\text { Maneiras de conduzir a leitura de textos e vídeos }\end{array}$ \\
\hline $\begin{array}{c}3 \\
\text { Por trás das ações dos } \\
\text { coordenadores }\end{array}$ & $\begin{array}{l}\text { Ações definidas com base nos interesses da Escola } \\
\text { Açoes definidas com base nas formações da DE } \\
\text { Açôes definidas com base nas demandas da SEE-SP }\end{array}$ \\
\hline
\end{tabular}

Fonte: Silva (2019, p. 109), com base na incidência das respostas e no número total de 380 participantes.

As subcategorias (categorias mais amplas) também foram organizadas em quadros para, subsequentemente, desenvolver a análise qualitativa do material. Por último, interpretamos os documentos agrupados com apoio na sistematização dos dados dos quadros, creditando os sentidos que os indicadores inferem ao objeto do estudo.

$\mathrm{Na}$ categoria 1 foram agrupadas todas as estratégias apontadas pelos coordenadores. Na categoria 2, selecionamos os comentários que apresentavam "o que se lê e o que se vê em ATPC", isto é, o conteúdo da formação.

Um dado que nos chamou a atenção ao proceder com a análise do material foi que muitos coordenadores não se limitaram apenas em informar na resposta à questão da Survey o que eles consideravam por estratégia formativa, mas relataram também os motivos que os levavam a adotar determinados procedimentos na formação. Assim, foi possível perceber que a definição das estratégias, bem como do que se lê e do que se vê em ATPC, é decorrente de alguns aspectos, dentre eles: plano pedagógico do $\mathrm{CP}$, seu roteiro formativo, projeto pedagógico da escola, Currículo, necessidades da escola, demandas da SEE-SP e da Diretoria Regional de Ensino. As declarações que apresentavam os motivos das suas ações formativas em ATPC foram agrupadas na categoria 3 "Por trás das ações dos coordenadores". Para contemplar os objetivos traçados para este artigo, selecionamos a discussão dos dados referente a primeira categoria. Os achados do estudo foram fundamentados em autores do campo da formação docente.

\section{Achados do estudo: estratégias de formação apontadas pelos coordenadores}


Varias respostas apontavam indícios de ações e estratégias de formação realizadas pelos coordenadores em ATPC. Agrupei as mais recorrentes em eixos temáticos, o que fez surgir subcategorias e por fim a categoria um: "Estratégias de formação docente". A Tabela 1 apresenta essa organização:

Tabela 1 - Agrupamento dos eixos temáticos da categoria "Estratégias de formação docente"

\section{Subcategoria: Prática docente como objeto de estudo}

$\mathbf{N}^{\circ} \%$

Análise de práticas

$30 \quad 8 \%$

Troca de experiências/ socialização/discussão/relato de experiências sobre a prática

$49 \quad 13 \%$

Debate

$24 \quad 6 \%$

Roda de conversa $13 \quad 3 \%$

Grupo colaborativo $6 \quad 2 \%$

Tematização da prática $25 \quad 7 \%$

Estudo de caso $24 \quad 6 \%$

Narrativas de professores

Problematização/ dinâmicas/ atividades desafiadoras/ sistematização $36 \quad 10 \%$

Seminários/aulas/oficinas de práticas realizadas pelos professores

$10 \quad 3 \%$

\section{Subcategoria: Análise de produções de alunos e propostas didáticas}

Homologia de processos

$21 \quad 6 \%$

Dupla conceitualização

$185 \%$

Análise de textos/ atividades dos alunos/ avaliações

$17 \quad 5 \%$

Fonte: a autora. As porcentagens foram calculadas com base na incidência de respostas e no número total de 380 respondentes

\subsection{Subcategoria: Prática docente como objeto de estudo}

Nessa subcategoria estão agrupadas todas as respostas relacionadas ao eixo temático: análise/reflexão/ problematização da prática. Um ponto em comum nesse eixo é que a formação do CP parte de situações problemáticas dos próprios professores, tendo por foco o estudo da prática docente.

Uma das estratégias mencionadas (8\%) foi a análise de práticas. No contexto das respostas, infere-se que a expressão 'prática' está comumente sendo utilizada pelos sujeitos como situações didáticas dos professores. Analisar envolve compreender as ações utilizadas 
pelos docentes no cotidiano da sala de aula. Para efeito de ilustração, separei duas respostas:

Solicito aos professores os desafios que enfrentam, as soluções encontradas por eles e que conceitos teóricos usaram para solucionar os desafios que se lhe apresentaram. Como segunda etapa, [...] estudamos os conteúdos teóricos pra contextualizá-los na prática de sala de aula [...] (CP 91).

Utilizo estratégias de acordo com o tema da reunião e com as necessidades dos professores. Costumo utilizar a tematização, a troca de experiências $e$ grupo colaborativo. Atualmente estamos analisando as práticas dos professores da própria escola. Eles apresentam o que estão fazendo e as dificuldades que estão tendo na sala de aula, então a gente discute quais atividades deram certo ou não, e quais são as mais adequadas. Percebo que assim consigo envolvê-los numa reflexão, explicitando a necessidade de estudar um conteúdo teórico ( $C P_{1161)}$.

Para analisar a prática docente, é possível perceber que os CP buscam os saberes de cada professor, por meio da observação do que eles apresentam, bem como solicitando que informem os desafios e as soluções encontradas. A estratégia possibilita, conforme o CP 161, envolver o grupo para discutir o que está dando certo ou não. Nota-se, nesse movimento, que ele não parte do estudo teórico, ao contrário, a teoria é introduzida para fundamentar a prática, dessa forma o CP afirma que está conseguindo envolver o grupo numa reflexão.

Para análise das práticas os coordenadores frequentemente associam a expressão troca de experiência ou sinônimos como relato de prática, socialização, discussão de prática. Esses termos reunidos surgiram em 23\% das respostas como observado a seguir:

Aprendizagem dialógica; Relatos de Prática; vídeos. Tento fazer coisas para estimular eles a participar do HTPC, pra eles trocarem experiências da prática. Quando eu era professora, sentia que a sala de aula era muito solitária. No HTPC é o único momento em que tá todo mundo mais junto. Sair da solidão é prioridade, tem que haver tempo para os educadores conversarem entre si (CP 347).

O horário de ATPC é destinado para promover a troca de experiência profissional possibilitando a reflexão sobre a pratica docente. Articular ações educacionais desenvolvidas pelos diferentes segmentos da escola. Acompanhar de forma sistemática o processo de ensino aprendizagem (CP 181).

O relato envolve expor, narrar, descrever ou comunicar experiências vivenciadas. É comum, em reuniões coletivas, os professores contarem o que estão realizando em sala de aula, seus trabalhos e projetos. Percebe-se, nas respostas dos CP 181 e 347, que essa ação é 
utilizada por eles de maneira intencional, com objetivo de "possibilitar a reflexão sobre a prática docente".

A troca de experiência de práticas profissionais é empregada por Charlier (2012, p. 95) como uma estratégia de formação: "a explicitação de sua prática permite ao professor tomar um distanciamento em relação a ela. A confrontação com as vivências dos colegas pode ser tanto uma fonte de reforços das teorias que subjazem à ação como estar no centro de um conflito e fomentar um questionamento". Nóvoa (2009) considera que a socialização de práticas é um passo importante, mas que a experiência de cada um só se transforma em conhecimento através da análise sistemática das práticas.

Assim, a estratégia possibilita a socialização dos saberes docentes; promove a articulação entre os participantes da ATPC e cria condições para que os professores "saiam da solidão", pois apesar de estarem inseridos em um ambiente com outros profissionais, o professor trabalha, quase sempre, isolado em sua sala de aula, como constata o CP 347.

Outras estratégias relacionadas à interação do grupo sobre aspectos da prática de sala de aula foram o debate (6\%), a roda de conversa (3\%) e o grupo colaborativo ( $2 \%)$. O CP 372 explica como faz uso do debate: "[...] além das discussões frequentes sobre questões colocadas por mim aos professores, eles também socializam suas práticas. Gosto de usar o debate de temas polêmicos, como no caso da avaliação e da indisciplina. Ouvir o que o outro tem a dizer amplia os horizontes".

Conforme Lerner (2012, p. 246), o debate a partir de questões sobre uma prática pedagógica, colocadas intencionalmente pelo formador, torna-se uma estratégia fecunda quando é utilizada de modo a "problematizar o ensino; por colocar explicitamente questões que merecem ser objeto de reflexão, por promover a partir delas o diálogo entre os diversos conhecimentos dos professores participantes, bem como entre estes e os saberes que se pretende ensinar". A estratégia privilegia a expressão e a capacidade de argumentação dos professores.

Em relação aos coordenadores que mencionaram grupo colaborativo, suas respostas são similares as do CP 132 "Trabalho com diferentes estratégias para incentivar e valorizar os saberes dos professores. Estas estratégias vão desde [...] apresentação dos professores aos seus pares [sobre] um determinado tema abordado, grupos colaborativos. [...]". Ou seja, a 
resposta não fornece elementos que permitam compreender se eles fazem uso dessa estratégia como preconiza Passos (2016)

Outra estratégia cujo objeto de estudo é o fazer docente é a tematização da prática mencionada por $7 \%$ dos coordenadores. Na maioria das vezes, os respondentes associam tal estratégia ao estudo de práticas

Costumo trabalhar temas que possam contribuir para melhorar o aprendizado dos alunos. As estratégias são variadas. Quase sempre começamos a reunião com uma leitura inicial, ou leitura compartilhada. Às vezes uso o estudo de caso, oficina de práticas dos professores, análise de práticas, como é o caso da tematização da prática. Leitura e estudo de textos teóricos quase sempre para complementar a discussão que fazemos do vídeo da aula que a gente assiste na tematização. Principalmente para os professores que trabalham com a alfabetização, destaco que é importante que eles saibam que, por trás de suas práticas pedagógicas, sempre há uma concepção de ensino e de aprendizagem ( $C P 7)$.

O estabelecimento de diálogo por acreditar que o processo formativo dialógico e dialético é aquele que, de fato, provoca mudanças. Estratégias como a tematização da prática são utilizadas com frequência, porém buscando refletir sobre as teorias que subjazem tais práticas e/ou que podem configurar-se como subsídios para ressignificação das práticas existentes (CP 367).

A análise de boas aulas documentadas, geralmente em vídeo, é uma característica particular da tematização da prática. O potencial dessa estratégia, conforme Weisz (2009) é o estudo sistemático de situações que acontecem na sala de aula de tal maneira que permita ao CP compreender as ideias e as hipóteses que guiam os atos do professor. Notase, nas respostas dos CP 7 e 367, essa preocupação em que os professores tenham consciência de suas teorias implícitas. O trabalho de tematizar a prática possibilita fazer aflorar essa consciência, ultrapassando a dicotomia certo ou errado que costuma marcar a análise da prática docente. Nesses dois comentários, a discussão sobre a análise/tematização da prática é fundamentada por meio de "leitura e estudo de textos" e "refletir nas teorias", com objetivo de criar condições para que os professores ressignifiquem suas ações. Tal ação pode oferecer quadros teóricos de referência ou constituírem-se pontos de partida para interpretar e avaliar situações novas. A ressignificação ou mudanças na prática, desejadas pelo CP 367, ocorrem, nessa perspectiva, "quando os professores

\footnotetext{
${ }^{3}$ Para Passos (2016), os grupos colaborativos são formados por pessoas que têm interesses comuns por determinado tema ou assunto, ainda que nem todos estejam interessados em abordá-lo com a mesma visão, pois a diversidade de opiniões contribui muito para a aquisição de novos conhecimentos.
} 
reconhecem discrepâncias entre a sua própria visão e a de outros participantes sobre os componentes do processo de ensino-aprendizagem" (MIZUKAMI; REALI, 2002, p. 77).

Para $6 \%$ dos coordenadores o Estudo de Caso é uma estratégia relevante para refletir sobre casos de ensino e para estimular a participação do grupo, como menciona o CP 262: [...] o bacana é fazer estudos de caso, pois os professores gostam bastante de participar. O CP 214 descreve como faz o trabalho com essa estratégia:

Sempre no início de cada semestre, realizo o levantamento das necessidades de formação dos professores e as principais defasagens dos alunos quanto a aprendizagem. Em determinados momentos solicito aos professores a leitura prévia de texto para serem debatidos posteriormente (no momento da formação), mas em outros momentos, leituras realizadas no momento da formação. Após a discussão com o grupo de professores (que pode durar mais de 2 htpcs) solicito a análise de um caso de ensino (estudo de caso) em grupo, com fundamentação na leitura e discussão realizada. Assim, após as analise, ocorrem as socializações das discussões em grupo (CP 214).

O CP 245 explica como consegue compor seu material para trabalhar com os professores: [utilizo] estudo de caso (casos trazidos por mim, procurados na internet, ou os casos podem ser de alunos da própria escola); [...].

Os coordenadores também citaram em $9 \%$ de suas respostas muitas atividades como: problematização, dinâmicas, atividades desafiadoras ${ }^{4}$, sistematização, entre outros; estas atividades não são exatamente estratégias formativas, mas procedimentos metodológicos que podem ser utilizados pelo formador durante as atividades. A problematização, por exemplo, pode ocorrer quando o CP faz intervenções planejadas, por meio de perguntas que estimulem o exercício metacognitivo; quando questiona colocações feitas pelos educadores, procurando fazê-los pensar nas concepções subjacentes; quando retoma uma discussão inicial para a qual não se deu fechamento ou informações conclusivas, para que o próprio grupo tente concluir com os recursos de que dispõe. É o que parece fazer o CP 196:

De forma geral, utilizo como estratégia formativa a "tematização da prática", com apresentação de situações concretas vivenciadas no cotidiano escolar $e$ problematização (questionamentos que fomentam a busca por soluções). Em

\footnotetext{
4 "desafiador é aquilo que é difícil e possível ao mesmo tempo, 'se queremos que os educadores expressem suas opiniões, temos que saber lidar com elas, especialmente quando são equivocadas, segundo o nosso ponto de vista. Não é possível, ao mesmo tempo, pretender que as pessoas falem e 'corrigi-las' publicamente quando elas o fazem, porque dessa forma elas com certeza deixarão de falar ou assumirão um papel de oposição. Por outro lado, é preciso saber 'dosar o nivel de desafio'"' (BRASIL, 2001).
} 
uma das etapas da ação formativa há sessão de estudo, sendo utilizados referenciais da Secretaria da Educação, para qualificar as reflexões (CP 196).

A postura problematizadora exige que o formador analise previamente a atividade que será discutida "formulando algumas questões que servem como uma espécie de roteiro para discussão [...] o objetivo é ajudar a explicitar, a tornar observáveis as ideias que, de forma consciente ou não, sustem o fazer do professor" (WEISZ, 2009, p. 126).

Os coordenadores também apontaram estratégias em que os professores são os protagonistas na elaboração e desenvolvimento de atividades que acontecem em ATPC, tais como: seminários, aulas realizadas por professores e oficinas de práticas; o conjunto dessas respostas foi de $3 \%$.

Gosto de deixar os professores 'dar aula no HTPC', percebi que quando eles só explicavam o que faziam não dava para entender muito bem suas atividades. Fazendo o passo a passo fica mais claro e dá pra discutir melhor as atividades. [...] (CP 99).

Oficinas de práticas realizadas pelos professores, para dinamizar e tornar interessante a formação com conteúdos sugeridos pelo grupo [...] (CP 280)

Conforme o CP 99, quando o professor se coloca em outra posição, assumindo a tarefa do formador no momento da reunião consegue mobilizar o grupo na discussão das atividades. Quando os docentes se tornam coparticipantes do processo formativo, não somente realizando as tarefas, mas "sugerindo o conteúdo" da reunião, conforme propõe o CP 280, é mais fácil que se sintam motivados, pois é algo que parte deles, de suas necessidades.

\subsection{Subcategoria: Análise de produções de alunos e propostas didáticas}

O espaço deste artigo não permitirá detalhar os "achados" desta subcategoria. Nessa subcategoria, separamos todas as respostas relacionadas às condições didáticas necessárias para ensino de um conteúdo em sala de aula. Uma característica comum nas estratégias desse eixo temático é que o objeto de estudo não é especificamente a prática docente, mas as atividades discentes. Assim, analisam-se as produções dos alunos com objetivo de planejar ou adequar propostas didáticas.

Lerner (2012b, p. 67) justifica a pertinência de atividades desse tipo no processo formativo "a tensão entre as necessidades relativas à aprendizagem dos alunos e as relativas à formação dos professores se apresenta de forma recorrente no processo 
formativo"; a análise e a elaboração conjunta da produção discente "permite atender simultaneamente aos dois polos da tensão".

\section{Considerações Finais}

Os dados da Survey possibilitaram identificar o que os sujeitos apontam por estratégia de formação. Isso significa que a grande maioria dos coordenadores demonstra conhecer e fazer uso dos dispositivos mencionados. Os dados também revelaram as dificuldades que os coordenadores têm em fazer da ATPC um momento de estudos, como indica o CP 276: Resolver problemas de salas. Não tem jeito, indisciplina é o tema que os professores querem discutir. Às vezes até trago leituras de textos teóricos para discussão[...]. Também estou procurando conhecer estratégias eficientes, quando vocês acharem, por favor, me avisem. As discussões sobre o comportamento e a indisciplina dos alunos parece ser o foco de interesse para muitos professores. De fato, os quatro coordenadores que acompanhei mais de perto nas quatro escolas em que observei a ATPC também sinalizaram esse fenômeno. É possível abordar essa problemática de uma maneira pedagógica? Sim. O referencial apresentado ao longo da pesquisa demonstrou caminhos. O CP 276 conclui que o que falta é "conhecer estratégias eficientes". Mas será que somente isso é suficiente? Não.

A teoria e o conhecimento didático-pedagógico colaboram para aprimorar nosso olhar e a capacidade de interpretar o que está se passando na escola; ajudam a compreender de forma mais fundamentada aquilo que está ocorrendo na interação do aluno com o conhecimento. Portanto, não se trata de entender as estratégias como uma aplicação ou prescrição, elas não devem funcionar como uma lista de exercícios ou dinâmicas para envolver os professores. O caminho para a formação crítico-reflexiva com foco no desenvolvimento profissional não está na estratégia, mas na concepção do coordenador sobre o que é formação. Se a concepção do coordenador se baseia na formação para o desenvolvimento de um profissional crítico e reflexivo, ele não conceberá o professor como alguém que aplica técnicas, ao contrário, sua ação será na perspectiva de ajudar o professor a avaliar, refletir e analisar criticamente sua prática.

A análise das estratégias mencionadas na Survey, à luz do referencial teórico da pesquisa, evidenciou que elas têm o potencial de mobilizar o grupo docente para uma 
reflexão crítica sobre a prática, uma vez que os encaminhamentos metodológicos previstos nesses dispositivos formativos possibilitam uma postura investigativa do professor, bem como uma reflexão crítica sobre seu trabalho em sala de aula. Mas de que modo esse processo está sendo conduzido? Se, de fato, os coordenadores estão conseguindo, por meio das estratégias mencionadas, promover junto ao grupo tal postura e a reflexão desejada é algo que este estudo não deu conta de verificar no espaço-tempo da pesquisa. No entanto, o enfoque das respostas dos coordenadores ou a perspectiva que eles apontam sobre a formação, permite inferir que suas concepções estão mais próximas de desenvolver ações de formação com o desejo de contribuir para o desenvolvimento profissional dos professores.

\section{Referências}

ALMEIDA, Laurinda R. Diretrizes para a formação de professores: uma releitura. In. ALMEIDA, L. R.; PLACCO, V. M. S. N. (orgs.). As relações interpessoais na formação de professores. $2^{\text {a }}$ ed. São Paulo: Edições Loyola, 2004.

ANDRÉ, Marli. Formar o professor pesquisador para um novo desenvolvimento profissional. In. ANDRÉ, Marli E. D. A. (org.). Práticas inovadoras na formação de professores. Campinas, SP: Papirus, 2016.

BARDIN, Laurence. Análise de conteúdo. $3^{\mathrm{a}}$ reimp. da $1^{\mathrm{a}}$ ed. São Paulo: Edições 70, 2016.

BRUNO, Eliane B. G.; CHRISTOV, Luiza H. S. Reuniões na escola: oportunidades de comunicação e saber. In. BRUNO, Eliane B. G.; ALMEIDA, Laurinda, R. CHRISTOV, Luiza H. S. O coordenador pedagógico e a formação docente. $4^{\mathrm{a}}$ ed. São Paulo: Edições Loyola, 2003 .

CANÁRIO, Rui. A escola: o lugar onde os professores aprendem. Revista Psicologia da Educação, São Paulo: Revista do Programa de Estudos pós-graduados PUC-SP, n. 6, p. 927, jan/jun. 1998.

A prática profissional da formação de professores. In: V Seminário fala outro escola. UNICAMP/FE-GEPEC, 2010.

CHARLIER, Évelyne. Formar professores profissionais para uma formação contínua articulada à prática. In. PAQUAY, L.; PERRENOUD, P.; ALTET, M. CHARLIER, E. (orgs.). Formando professores profissionais: Quais estratégias? Quais competências? $2^{\mathrm{a}}$ ed. rev. Porto Alegre: Artmed, 2001. 
GARCÍA, Carlos M. Formação de professores para uma mudança educativa. Portugal: Porto Editora, 1999.

HUBERMAN, Michael. O ciclo de vida profissional dos professores. In: NÓVOA, António (Org.). Vidas de professores. $2^{\text {a }}$ ed. Porto: Porto, 1995. p. 31-61.

IMBERNÓN, Francisco. Formação continuada de professores. Porto Alegre: Artmed, 2010.

Formação docente e profissional: formar-se para a mudança e incerteza. 9a ed. São Paulo: Cortez, 2011.

LERNER, Délia. Percursos didáticos na formação. In. CARDOSO, Bia; LERNER, Délia; NOGUEIRA, Neide. Ensinar: tarefa para profissionais. $2^{\mathrm{a}}$ ed. Rio de Janeiro: Record, 2012.

MARCELO, Carlos. Desenvolvimento Profissional Docente: passado e futuro. Sísifo - Revista de Ciências da Educação, $\mathrm{n} .{ }^{\circ} 8$. j a $\mathrm{n} / \mathrm{a}$ b $\mathrm{r}$ 2009. Disponível em http://www.unitau.br/files/arquivos/category_1/MARCELO_Desenvolvimento_Profissional_ Docente_passado_e_futuro_1386180263.pdf acesso em 10/08/2017.

MIZUKAMI, Maria G.; REALI, Aline M. M. R. (Orgs.) Formação de professores, práticas pedagógicas e escola. São Carlos: EdUFSCar, 2002.

MOSCOSO, Javier N. Los métodos mixtos en la investigación en educación: hacia un uso reflexivo. Cadernos de Pesquisa, v.47, n.164, p. 632-649, abril/junho 2017.

NÓVOA, Antônio. Formação de professores e profissão docente. In. Nóvoa, A. Os professores e sua formação. Lisboa: Dom Quixote, 1995.

Professores: Imagens do futuro presente. Lisboa: Educa, 2009.

OLIVEIRA-FORMOSINHO, Julia. Desenvolvimento profissional dos professores. In: FORMOSINHO, João (coord.). Formação de professores: aprendizagem profissional e ação docente. Porto: Porto Editora, 2009.

PASSOS, Laurizete F. Práticas formativas em grupos colaborativos: das ações compartilhadas à construção de novas profissionalidades. In. ANDRÉ, M. (org.) Práticas inovadoras na formação de professores. Campinas, SP: Papirus, 2016.

PLACCO, Vera M. N. S. ; SOUZA, V. L. T. (orgs.). Aprendizagem do adulto professor. São Paulo: Edições Loyola, 2006.

SILVA, Jeanny M. S. Diferentes caminhos para formação docente estratégias empregadas por coordenadores pedagógicos. 279f. 2019. Tese (Doutorado em Educação: Psicologia da Educação), Pontifícia Universidade Católica de São Paulo, São Paulo, 2019. ZEICHNER, Kenneth. Para além da divisão entre professor-pesquisador e professoracadêmico. In: GERALDI, Corinta M. G.; FIORENTINI, Dario; PEREIRA, Elisabete, M. A Cartografias do trabalho docente. Campinas, SP: Mercado das Letras, 1998. 
WEISZ, Telma. O diálogo entre o ensino e a aprendizagem. $2^{\text {a }}$ ed. São Paulo: Ática, 2009.

\footnotetext{
' Pós-doutoranda em Educação Formação de Formadores da PUC-SP e Doutora em Psicologia da Educação pela mesma instituição. Professora de pós-graduação e da educação básica.

E-mail: jeanny.sombra@hotmail.com
} 